\title{
Research on Public Health Emergency of International Concern Under International Law-Take COVID-19 as an Example
}

\author{
Yumeng Zhang ${ }^{1}$ \\ ${ }^{1}$ College of Humanities \& Development, China Agricultural University, CAU, Beijing, China,100083 \\ *Corresponding author. E-mail: 781208552@qq.com
}

\begin{abstract}
COVID-19 broke out in January 2020 and has been declared a "Public Health Emergency of International Concern(PHEIC)" by World Health Organization(WHO). Up to now, it is still spreading in the global scope, which is also a severe test for the international public health governance system. Taking Corona Virus Disease(COVID-19) as an example, this paper attempts to study the response mechanism of PHEIC under the current norms of international health law and understand the content and characteristics of PHEIC in IHR as well. At the same time, the article selects two major problems about unequal distribution of health resources and excessive epidemic prevention and health measures which exposed during the epidemic to discuss. Then, through reading articles of other scholars, some feasible suggestions for modifying IHR in the future were put forward. This paper also compares and analyzes some real data collected during the epidemic period, and tries to analyze the differences between international law norms and the actual behavior of governments and international organizations in the face of the epidemic. The results show that the reason lies not only in the imperfection of international law norms and regulatory system, but also in the unbalanced development among countries. Consequently, in order to improve the PHEIC mechanism, it is necessary to strengthen the constraints of international law on all parties, and at the same time, it is useful to pay attention to the core national capacity, that is, countries should strive to improve their basic medical level.
\end{abstract}

Keywords: International Law; World Health Organization; International Health Regulations; Public Health Emergency of International Concern; COVID-19 pandemic.

\section{INTRODUCTION}

The director-general of the WHO convened a second Emergency Committee meeting on January 302020 and declared the COVID-19 outbreak a PHEIC. Globally, as of 4:06 pm CEST, 18 August 2021, there have been over 208 million confirmed cases of COVID-19, including more than 4 million deaths, reported to WHO. As of 18 August 2021, a total of more than 4.5 billion vaccine doses have been administered[1]. PHEIC was created in order for the international community to have a basis in the face of global infectious diseases in the context of globalization.

However, due to the complex interests of all parties involved, both positive and negative effects have been generated, and a lot of international cooperation is needed, which greatly tests individual capabilities, cooperative attitudes and organizational leadership of all countries. Therefore, many problems have been exposed during the COVID-19 epidemic. Accordingly, this paper studies the PHEIC response mechanism from the perspective of international law norms. The paper will first outline the specific content and characteristics of PHEIC under the current global health governance system, and then discuss the problems exposed in the application of the PHEIC system in COVID-19, and discuss possible solutions. This may help the international community in the future when it encounters similar public health events, as well as better leverage the role of international law and international organizations such as the WHO. 


\section{THE CONCEPT AND CHARACTERISTICS OF PHEIC UNDER INTERNATIONAL LAW}

\subsection{The Specific Concept of PHEIC}

PHEIC, as proposed by IHR(2005), has been declared six times over the past decade, the most recent being COVID-19 outbreak. The 2005 revision of the IHR first regulated PHEIC as a legal concept, triggered when it constitutes a public health risk to other countries and may require a coordinated international response.

Concerning PHEIC, the obligations of states parties at the level of international law mainly fall into the following six aspects: first, States Parties should pay WHO contributions on time; second, at the request of WHO, States Parties should support to the greatest extent possible the coordinated response activities of their organizations; third, States Parties shall assess PHEIC promptly and notify WHO as required; forth, each State Party shall have a dedicated unit responsible for implementing the IHR and able to maintain contact with the IHR focal point; fifth, States Parties shall, within a specified period, explain to WHO the rationale and relevant scientific information for additional health measures that significantly interfere with international traffic; sixth, to the extent possible, States Parties shall cooperate in the detection and assessment of PHEIC and the implementation of response measures.

\subsection{One of the Characteristics of PHEIC}

From the process of the evolution of the legal mechanism of PHEIC international cooperation, its progress to a large extent is to promote the transformation of international cooperation moral obligation to international cooperation legal obligation based on content similarity[2]. Convert some of the moral obligations of international cooperation into legal obligations, most notably the dissemination of information and data on the epidemic, as well as health measures are taken, from moral obligations to legal obligations. For example, Article 6 (1) of the IHR (2005) specifies the events, time-frames and procedures that may constitute the assessment and notification to WHO of a PHEIC; The second paragraph provides for specific items to be reported in respect of notified incidents. But, judging from the treaty text, similar transformations are not common. The norms of international law have no further provisions in many key areas, so many obligations of international cooperation can only remain at the moral level.

\section{THE APPLICATION AND EXPOSED PROBLEMS OF PHEIC DURING COVID- 19 PANDEMIC}

\subsection{Unequal Health Resources Distribution}

In the early days of the COVID-19 outbreak, many countries experienced a shortage of virus test kits. Now, many countries are facing a shortage of vaccines. Developing countries have long been unhappy with the global sharing of virus samples. In early 2007 , Indonesia has announced that it would stop providing strains of the $\mathrm{H} 5 \mathrm{~N} 1$ virus to foreign laboratories which caused quite a stir. Indonesian authorities believed, they isolated the virus samples, after entering the global influenza surveillance system by some companies to use for the new vaccine development, finally to developing countries to afford the price of selling the vaccine. Lack of trust is the most important thing to avoid in international cooperation, which is caused by the contradiction between the profit-making of enterprises and the public welfare of health resources. In addition, public health resources are influenced by a country's medical and economic levels. IHR (2005) does not make specific requirements for the fair allocation of public health resources, which means that WHO has no legal basis to make requirements for the reasonable allocation of public health resources, and states parties have no legal obligation to assist other countries.

The data in table 1 which from WHO website shows that more than 4.5 billion doses of COVID-19 vaccine have been administered globally by August 20, 2021, with roughly 73 percent of the vaccines in 10 wealthy countries (according to the 2019 national GDP ranking), while the coverage rate in low-income countries is only around 1 percent. This largely reflects the fact that the distribution of vaccines is constrained by the state of the country's economic development. But universal vaccination is the safest and most effective way to control the spread of an epidemic.

Table 1: Vaccine doses administered in ten richest countries (as at 20 August 2021)

\begin{tabular}{|c|c|c|}
\hline Country & Vaccine doses administered & Percentage of total(\%) \\
\hline United States of America & $355,480,412$ & 3.8 \\
\hline China & $1,776,816,416$ & 1.8 \\
\hline Japan & $84,009,438$ & 2.2 \\
\hline Germany & $97,884,043$ & 39.1 \\
\hline
\end{tabular}




\begin{tabular}{|c|c|c|}
\hline India & $560,652,030$ & 12.3 \\
\hline The United kingdom & $86,611,177$ & 1.9 \\
\hline France & $80,791,094$ & 1.8 \\
\hline Italy & $74,012,351$ & 1.6 \\
\hline Brazil & $152,806,767$ & 3.4 \\
\hline Canada & $51,241,661$ & 1.1 \\
\hline Global & $4,543,716,443$ & 100 \\
\hline
\end{tabular}

In May 2020, China proposed that vaccines should become a "global public good", and this idea has also been accepted by WHO. This does not mean that vaccine patents should be completely free, but that vaccines for PHEIC could be available to people in every country and region at a reasonable price.

In order to make up for the deficiencies of the IHR in dealing with PHEIC, and to better solve the problem of unequal resource sharing and allocation, WHO has also made a series of initiatives.

In May 2020, WHO and partners launched the COVID-19 Technology Access Pool (C-TAP) to boost COVID-19 health products[3]. Besides, at the end of April 2020, WHO as the lead organization launched the Access to COVID-19 Tools ACT-Accelerator (ACTAccelerator) _ a global collaboration to accelerate the development, production, and equitable access to COVID-19 tests, treatments, and vaccines[4]. And then, COVAX facility was built under this framework is Global procurement for COVID-19 vaccines[5]. They planed to deliver 2 billion vaccine doses, of which 1 billion will be purchased for LMICs, by the end of 2021. But as of mid-July, only about 100 million doses had been delivered to 135 countries and territories, or about $3 \%$ of the global total, and African countries had received only 65 million doses[6].

\subsection{Unreasonable Restrictive Epidemic Prevention and Health Measures}

By Articles 12 and 15 of the IHR, the director-general of WHO may, when declaring a health event to constitute a PHEIC, provide interim and long-term advice to prevent the spread of disease and avoid unnecessary interference with international traffic. On 30 January 2020, when the WHO declared the spread of COVID-19 a public health emergency, the Emergency Committee did not recommend that WHO member States impose any travel or trade restrictions. However, this is only the recommendation of the $\mathrm{WHO}$ and does not have the effect of prohibiting member States from adopting travel or trade restrictions. Meanwhile, according to Article 43 of the IHR, countries can decide for themselves whether to adopt more stringent health and quarantine measures than those recommended by the WHO, based on their respective sovereignty, their assessment of the impact of the outbreak and their own acceptance of the risk of transmission[7]. However, states parties shall provide WHO with public health evidence and relevant scientific information within 48 hours of taking additional health measures that significantly interfere with international traffic. Unfortunately, the IHR does not specify the liability for breach of this obligation. Therefore, it is difficult for PHEIC to play a larger role under the existing international law framework.

A commentary published online in the Lancet on 13 February 2020 by 16 globally influential health jurists states: "Many travel restrictions imposed during the COVID-19 outbreak are not supported by science or by WHO. Travel restrictions on this virus have been questioned by public health researchers. In terms of procedures, "at least two-thirds of these countries have not reported their additional health measures to WHO"[8]. Now, more than ever, it is important to uphold the rules of international law that require states to begin to lift the illegal travel restrictions that have been put in place, to support WHO, and to support each other as they comply with the IHR[9].

After the COVID-19 outbreak, many countries have imposed restrictions not only on international travel, but also on international transport. If restrictions on international travel and quarantine for travellers from high-risk areas are relatively reasonable measures to prevent widespread spread of the virus, there must be a clear irrationality in restrictions on international cargo transport, In particular, direct restrictions on trade with affected countries and regions may violate the General Agreement on Tariffs and Trade(GATT) and the Agreement of Sanitary and Phytosanitary Measures(SPS). As a result of COVID-19, the global recession and unemployment will be worse than the 2008 global financial crisis[2]. Given that restricting international trade would clearly hit the world economy, countries should choose the least restrictive measures to contain the epidemic[7].

Thus can be seen that the current coordination mechanism for infectious disease control is fragmented. Countries cannot beggar-thy-neighbor by blocking the source of the virus only at their borders. Even if a country succeeds in stopping the spread of the disease, as long as 
it persists, the bad situation in other countries will affect that country both in terms of its overall economy and fragile global supply chains[10].

\section{SUGGESTION}

The most direct way to improve the PHEIC response mechanism would be to improve the IHR. In addition to the revision of previous treaties, it is also necessary to consider the signing of new international treaties in the field of health, and to convert more moral obligations of countries into legal obligations, so as to give full play to the role of international law[11].

First, a mechanism for coordinating human, financial and financial resources during PHEIC emergencies should be established, which is crucial for less developed countries and regions to deal with PHEIC. This coordination mechanism could be a temporary department established by WHO after the announcement of PHEIC, rather than a permanent body, with the main purpose of balancing public health resource allocation among countries. In addition, WHO should be given more power through international treaties to give full play to its leading role in the international health governance system. In this way, WHO can better cooperate with other international organizations, non-governmental public welfare organizations, enterprises and individuals.

Second, there should be a standard for assessing the soundness of health measures in States parties. This means that data on the number of cases, rate of transmission, mortality, vaccination rates and so on during an outbreak can be correlated with the type and level of public health measures. In this way, in the event of PHEIC, States parties can quantify the situation of the epidemic in their countries and choose more appropriate preventive health measures based on reference.

Finally, a mechanism for monitoring and dispute resolution in the field of global public health can be established, which can not only monitor and review the legality of the restrictive epidemic prevention and health measures implemented by countries during PHEIC, but also mediate or arbitrate, or even punish, states parties that violate relevant international law. Such a mechanism could make up for the lack of punitive measures in existing international law. Of course, the specific form and procedure need further study.

\section{CONCLUSION}

In short, PHEIC is a common threat to all mankind and no country is immune from it. The prevention and treatment of infectious diseases require deep cooperation of the international community, and the norms of international law still need to be improved. In the postepidemic era, neither the existing international conventions nor the relevant documents issued by WHO are sufficient to address the problem of PHEIC. Furthermore, global prevention and treatment of infectious diseases depend on the level of medical resources in the host country, which is the national core capacity repeatedly emphasized by WHO. Therefore, in dealing with PHEIC, in order to promote more equitable distribution of public health resources, we should not only consider the improvement of international health law and international cooperation, but also pay attention to the balanced development of all countries in the world, fundamentally improve the level of medical treatment, and enhance the capacity to deal with PHEIC and other health challenges.

Finally, in order for countries to implement health measures more rationally, it is necessary to strengthen international law to avoid unnecessary panic caused by the announcement of PHEIC. Globalization is an irreversible trend of world development, and only by converting more moral obligations into legal obligations can we protect the PHEIC occurrence countries and other relevant countries, maintain world trade freedom, and form a more stable international environment.

\section{REFERENCES}

[1] WHO. https://covid19.who.int

[2] Liu Caikuan. International Law Review and institutional Innovation of International Cooperation in Response to Non-traditional Security Threats-From the Perspective of PHEIC[J].Tribune of Political Science and Law,2020,38(06):138-147.

[3] WHO. Novel WHO COVID-19 Technology Access Pool.[EB/OL].https://www.who.int/initiatives/covi d-19-technology-access-pool

[4] WHO. Novel What is the ACT-Accelerator. [EB/OL]. https://www.who.int/initiatives/actaccelerator/about

[5] WHO. Novel COVAX. [EB/OL]. https://www.who.int/initiatives/actaccelerator/covax

[6] WHO. Novel ACT-Accelerator update. [EB/OL]. https://www.who.int/news/item/26-06-2020-actaccelerator-update

[7] Bian Yongmin. Response to COVID-19 under International Law $[\mathrm{J}]$. Law Science Magazine,2020,41(04):12-21.

[8] Xu Junhua. On the Application of International Air Travel Restriction in the Case of PHEIC [J].Tribune of Political Science and Law,2021,39(02):90-102.

[9] The Lancet, Do not violate the International Health Regulations during the COVID-19 outbreak. https://www.thelancet.com/journals/lancet/article/P IIS0140-6736(20)30373-1/fulltext 
[10] Qin Qian, Luo Tianyu. The COVID-19 pandemic and international law [J]. Journal of the Central Institute of Socialism ,2020(03):104-108.

[11] Blinken Antony J.,Becerra Xavier. Strengthening Global Health Security and Reforming the International Health Regulations: Making the World Safer From Future Pandemics[J]. JAMA,2021.15611. 